\title{
Combining Metal-Metal Cooperativity, Metal-Ligand Cooperativity and Chemical Non-Innocence in Diiron Carbonyl Complexes
}

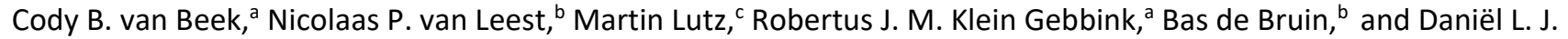 \\ Broere*a \\ ${ }^{a}$ Organic Chemistry and Catalysis, Debye Institute for Nanomaterials Science, Faculty of Science, Utrecht University \\ Universiteitsweg 99, 3584 CG, Utrecht (The Netherlands) \\ ${ }^{b}$ Homogeneous, Supramolecular and Bio-Inspired Catalysis Group, Van 't Hoff Institute for Molecular Sciences, \\ University of Amsterdam, Science Park 904, 1098 XH Amsterdam (The Netherlands) \\ c Structural Biochemistry, Bijvoet Centre for Biomolecular Research, Faculty of Science, Utrecht University \\ Universiteitsweg 99, 3584 CG, Utrecht (The Netherlands)
}

\begin{abstract}
Several metalloenzymes, including [FeFe]-hydrogenase, employ cofactors wherein multiple metal atoms work together with surrounding ligands that mediate heterolytic and concerted proton-electron transfer (CPET) bond activation steps. Herein, we report a new dinucleating PNNP expanded pincer ligand, which can bind two low-valent iron atoms in close proximity to enable metal-metal cooperativity (MMC). In addition, reversible partial dearomatization of the ligand's naphthyridine core enables both heterolytic metal-ligand cooperativity (MLC) and chemical non-innocence through CPET steps. Thermochemical and computational studies show how a change in ligand binding mode can lower the bond dissociation free energy of ligand $\mathrm{C}\left(s p^{3}\right)-\mathrm{H}$ bonds by $\sim 25 \mathrm{kcal} \mathrm{mol}^{-1}$. H-atom abstraction enabled trapping of an unstable intermediate, which undergoes facile loss of two carbonyl ligands to form an unusual paramagnetic $(S=1 / 2)$ complex containing a mixed-valent iron( 0 -iron $(I)$ core bound within a partially dearomatized PNNP ligand. Finally, cyclic voltammetry experiments showed that these diiron complexes show catalytic activity for the electrochemical hydrogen evolution reaction. This work presents the first example of a ligand system that enables $M M C$, heterolytic MLC and chemical non-innocence, thereby providing important insights and opportunities for the development of bimetallic systems that exploit these features to enable new (catalytic) reactivity.
\end{abstract}

\section{Introduction}

Various active sites in metalloenzymes feature cofactors with a multinuclear assembly that catalyze challenging chemical transformations at ambient conditions. ${ }^{1}$ A notable example is [FeFe]-hydrogenase which contains an active site comprising two iron centers that are connected by a bridging azadithiolate ligand. ${ }^{2}$ This enzyme rivals the efficiency of the platinum group metals for both $\mathrm{H}_{2}$ oxidation of and $\mathrm{H}_{2}$ production from protons and electrons. ${ }^{3}$ The extraordinary catalytic activity of [FeFe]-hydrogenase is the result of a combination of structural features in the inner and outer coordination sphere of the active site. ${ }^{4}$ These include the azadithiolate mediated heterolytic cleavage of $\mathrm{H}_{2}$ through metal-ligand cooperativity $(\mathrm{MLC}),{ }^{5}$ the close proximity between the $\mathrm{Fe}$ centers that allows for metal-metal cooperativity $(\mathrm{MMC}),{ }^{2}$ and long-range concerted protonelectron transfer (CPET) steps. ${ }^{6}$

Inspired by nature's multinuclear cofactors, a renewed interest in the synthesis and study of bimetallic systems is observed in recent years. ${ }^{7}$ The utilization of synthetic complexes wherein multiple metals work together to activate chemical bonds is a promising avenue to stabilize reactive species or develop new chemical transformations. ${ }^{8}$ The increased popularity for studying multimetallic complexes is evident by a wide range of ligand scaffolds designed to accommodate multiple metal centers that have recently been reported. ${ }^{7,8,9}$ Ligands based on 1,8-naphthyridine have been shown to be highly suitable for the synthesis of bimetallic complexes capable of MMC. ${ }^{10}$ However, even with these 'privileged' platforms binding of two metals in close proximity can present challenges on its own.

A more established avenue wherein chemists have drawn inspiration from nature involves the application of ligand systems containing design features for MLC. Such cooperative substrate activation through MLC is a welldeveloped concept in homogeneous catalysis. ${ }^{11}$ The two main strategies involve proton-responsive ligands that facilitate bond heterolysis over the ligand and metal ${ }^{12}$ or redox non-innocent ligands that can participate in electron transfer processes. ${ }^{13}$ In recent years researchers have developed ligand systems that can enable both MMC and MLC for the activation of chemical bonds. Most prominently, the group of Uyeda has demonstrated how dinickel complexes of a redox non-innocent 1,8naphthyridinediimine-based ligand can catalyze chemical transformations with superior activity and selectivity or distinct reactivity from what is possible with mononuclear analogues. ${ }^{14}$ This demonstrates the potential of ligand 
systems that can both accommodate two metal atoms in close proximity and display redox non-innocence (Figure 1, top). Along these lines our group has recently reported a proton-responsive 1,8-naphthyridine-derived 'expanded pincer' ligand, tBuPNNP, which can bind two metal atoms and enables heterolytic cooperative $\mathrm{H}_{2}$ cleavage on a dicopper(I) complex (Figure 1, middle). ${ }^{15}$

A less-explored MLC strategy involves the use of chemically non-innocent ligands that can act as both a proton and electron donor or acceptor through concerted proton-electron transfer (CPET) processes. ${ }^{16}$ The utilization of CPET steps in catalytic cycles is a strategy exploited by various natural systems and circumvents the formation of high-energy charged intermediates that result from sequential electron and proton transfer steps. ${ }^{17}$ Systems that can combine MMC for the binding and activation of substrates together with CPET steps through ligand chemical non-innocence could enable new or more efficient catalytic chemical transformations. However, to the best or our knowledge, no ligand systems that can combine these elements have been reported to date.

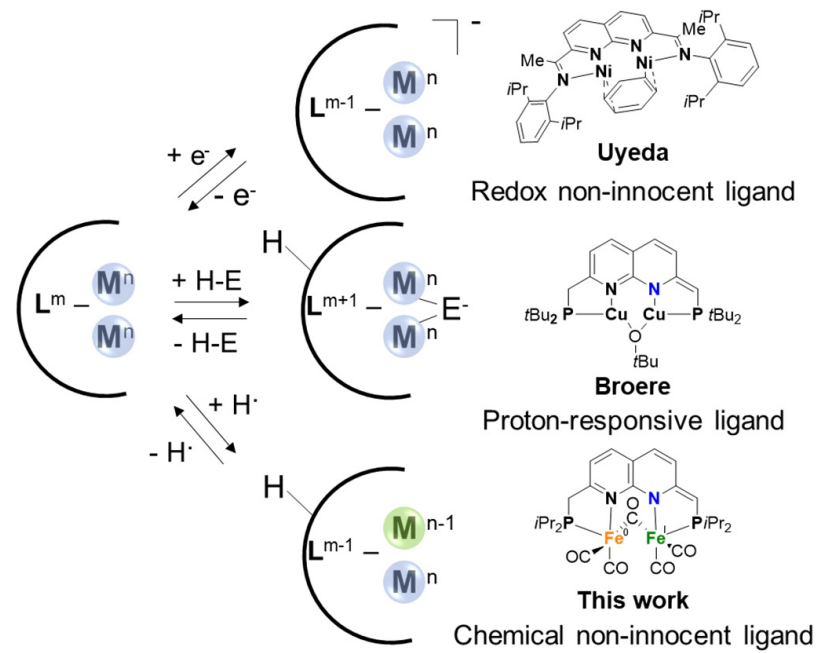

Figure 1: Different methods of metal-ligand cooperativity in bimetallic complexes.

Herein, we describe the synthesis and coordination chemistry of dinuclear iron(0) carbonyl complexes of a new iPrPNNP ligand. Like the related dicopper analogues, the ligand methylene linkers in these complexes can be deprotonated concomitant with partial dearomatization of the naphthyridine core. In addition, we show that the expanded pincer ligand displays chemical non-innocence in CPET reactivity, and that the binding mode of the ligand drastically affects the $\mathrm{C}\left(s p^{3}\right)-\mathrm{H}$ bond strength. This feature can be leveraged to enable binding of two iron-carbonyl centers in close proximity, which proved challenging via other methods. Finally, we show that the diiron complexes enable the same three features that are key to the function of [FeFe] hydrogenase - i.e. proton-responsive MLC, MMC and CPET (albeit long range) steps - and are also active catalysts for the electrochemical hydrogen evolution reaction (HER).

\section{Results \& Discussion}

Synthesis and reactivity

The 2,7-bis((diisopropylphosphaneyl)methyl)-1,8-naphthyridine (iPrPNNP) ligand was prepared as an air sensitive offwhite solid in $41 \%$ yield through a procedure analogous to that previously reported for the tBuPNNP ligand (see ESI for

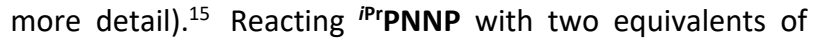
$\mathrm{Fe}_{2}(\mathrm{CO})_{9}$ in THF at ambient temperature (Scheme 1) results in the formation of a dark green solution. Analysis of the reaction mixture after $3 \mathrm{~h}$ by ${ }^{31} \mathrm{P}\left\{{ }^{1} \mathrm{H}\right\}$ and ${ }^{1} \mathrm{H} N M R$ spectroscopy shows the formation of an approximately equimolar mixture of nonsymmetric $\left[\mathrm{Fe}_{2}\left({ }^{(\mathrm{Pr} P N N P}\right)(\mathrm{CO})_{7}\right]$ (1) and (on average) $C_{2 v}$-symmetric [ $\mathrm{Fe}_{2}\left({ }^{\left({ }^{P r} P N N P\right)}(\mathrm{CO})_{8}\right]$ (2). Prolonged reaction times or heating the reaction mixture to reflux in THF did not change the ratio between 1 and 2 . Nonsymmetric complex 1 was isolated as an air-sensitive dark green solid in $26 \%$ yield by crystallization from toluene at $-40{ }^{\circ} \mathrm{C}$. The ${ }^{31} \mathrm{P}\left\{{ }^{1} \mathrm{H}\right\}$ NMR spectrum of 1 in $\mathrm{C}_{6} \mathrm{D}_{6}$ at $298 \mathrm{~K}$ shows two singlets at $\delta=93.6$ and $86.5 \mathrm{ppm}$, which are shifted downfield compared to free ${ }^{\text {iPrPNNP. This implies }}$ coordination of both phosphorous atoms to iron centers. ${ }^{18}$ The ${ }^{13} \mathrm{C}\left\{{ }^{1} \mathrm{H}\right\}$ NMR spectrum features the expected number of resonances for a nonsymmetric species, but only two resonances corresponding to CO ligands at $\delta=225.8$ and $214.2 \mathrm{ppm}$ are found. This implies that the axial and basal carbonyl ligands on each metal center are in rapid exchange with each other, causing averaging to a single resonance. ${ }^{19}$ The IR spectrum of complex $\mathbf{1}$ shows six bands in the carbonyl region, consistent with the incorporation of more than one iron carbonyl fragment. Three $\mathrm{CO}$ bands are assigned to the iron tricarbonyl fragment ${ }^{20}$ and three are expected for a $\mathrm{R}_{1} \mathrm{Fe}(\mathrm{CO})_{4}$ fragment, ${ }^{21}$ which is consistent with the NMR spectra and solid-state structure of 1 (see figure 3 and ESI for detail). Although $C_{2 v}$-symmetric complex $\mathbf{2}$ was not isolated, it could be obtained as the major species in a 0.85 : 0.15 mixture with complex 1 following a series of extractions. Spectroscopic analyses of $\mathbf{2}$ (see ESI) and its reactivity (see below) agree with its proposed structure (Scheme 1).

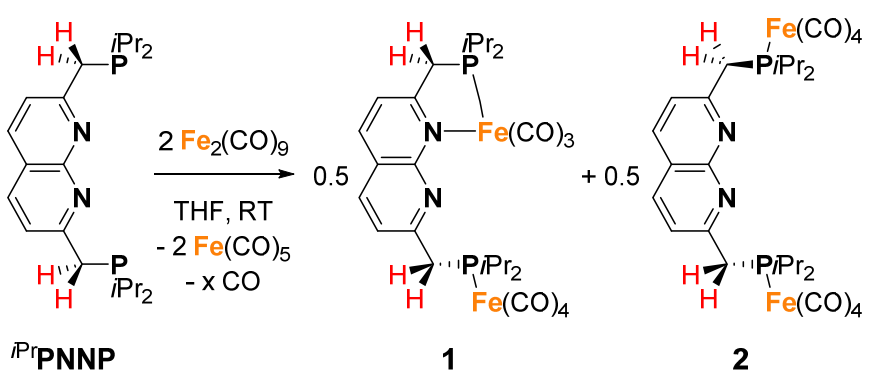

Scheme 1: Synthesis of complexes 1 and $\mathbf{2}$ by reaction of iPrPNNP with $\mathrm{Fe}_{2}(\mathrm{CO})_{9}$. 
To investigate the proton-responsive behavior of the ${ }^{\text {iPrPNNP }}$ ligand in $\mathbf{1}$, its reactivity towards bases was investigated. The addition of 1.1 equiv KOtBu to a dark green solution of $\mathbf{1}$ in THF at ambient temperature results in immediate formation of a dark red solution due to the formation of complex $\mathrm{K}(\mathrm{THF})_{\times}\left[\mathrm{Fe}_{2}\left({ }^{\text {iPrPNNP*}}\right)(\mathrm{CO})_{7}\right]$ (3). Complex $\mathbf{3}$ was isolated as a red-brown air- and water sensitive solid in $67 \%$ yield (Scheme 2). The ${ }^{31} \mathrm{P}\left\{{ }^{1} \mathrm{H}\right\}$ NMR spectrum of $\mathbf{3}$ in THF- $d_{8}$ at 298 $\mathrm{K}$ displays two closely spaced singlets at $\delta=82.6$ and 82.4 ppm. The deprotonation of one of the ligand methylene linkers in $\mathbf{3}$ is evident from the two characteristic doublets at $\delta=4.01 \mathrm{ppm}\left({ }^{2} J_{\mathrm{H}, \mathrm{P}}=3.2 \mathrm{~Hz}\right)$ and $\delta=3.40 \mathrm{ppm}\left({ }^{2} J_{\mathrm{H}, \mathrm{P}}=8.9 \mathrm{~Hz}\right)$ with an integral ratio of $1: 2$, respectively. Additionally, an upfield shift of the naphthyridine ${ }^{1} \mathrm{H}$ NMR resonances is observed, consistent with partial dearomatization of the ligand backbone. ${ }^{15}$ Similar to 1 , the ${ }^{13} \mathrm{C}\left\{{ }^{1} \mathrm{H}\right\}$ NMR spectrum of 3 in THF- $d_{8}$ at $298 \mathrm{~K}$ features only two resonances for the carbonyl ligands at $\delta=231.6$ and $216.1 \mathrm{ppm}$. Compared to 1 and $\mathbf{2}$ the CO stretching vibrations in $\mathbf{3}$ are less well separated in the IR spectrum, but show a largely unaffected $\mathrm{Fe}(\mathrm{CO})_{4}$ fragment and slightly red-shifted vibrational energies for the $\mathrm{Fe}(\mathrm{CO})_{3}$ fragment. The latter is consistent with the expected increase in $\pi$-backdonation in the $\mathrm{Fe}(\mathrm{CO})_{3}$ fragment. Together these observations show that there is no change in binding to both iron centers beyond the change from a neutral to a mono-anionic ligand bound to the tricarbonyl iron fragment, and this is in agreement with the solid-state structure (see Figure 3 ). In the solid state, $\mathbf{3}$ forms a one-dimensional coordination polymer with the anionic complex linked by potassium in a chain (Figure S88). The potassium ion is stabilized by coordination of two bound THF molecules, three carbonyl $O$ atoms, and the $\pi$-system of the naphthyridine. Interestingly, the potassium ion is almost equidistant to both the oxygen atom (K1-01 $=3.050(4) \AA$ ) and carbon atom $(\mathrm{K} 1-\mathrm{C} 23=3.172(5) \AA)$ of one of the carbonyl ligands. This is a rare case of a side-on coordinated carbonyl ligand of which only a handful of examples have been reported. ${ }^{22}$ Partial dearomatization of the ${ }^{\text {iPr}}$ PNNP ligand is evident by shortening of the C1-C2 bond (1.364(7) $\AA$ ), which is 0.131(7) A shorter than in 1 and the C9-C10 bond (1.514(6) $\AA$ ) within the same molecule. In addition, localized double bonds in the dearomatized ring (Table S4) and the shortened C1-P1 bond length of 1.781(5) Å are observed,

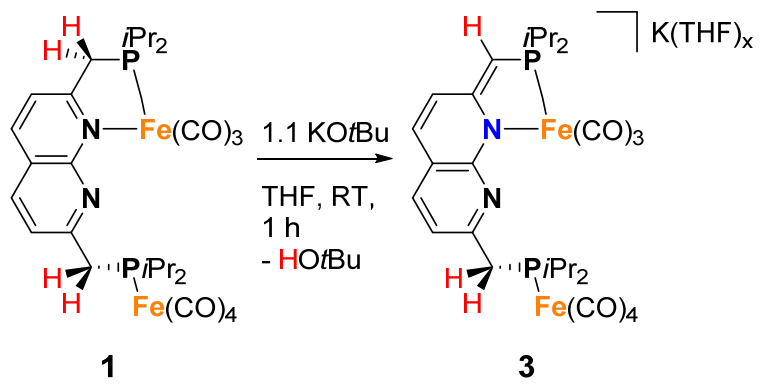

Scheme 2: Synthesis of $\mathbf{3}$ by deprotonation of $\mathbf{1}$. which are distinct features of a partially dearomatized iPrPNNP* ligand. ${ }^{15}$

As we were interested in studying the chemistry of diiron complexes wherein both metal centers are bound in the naphthyridine binding pocket, we pursued various strategies to remove $\mathrm{CO}$ ligands from isolated 1 . Routes involving the use of $\mathrm{N}$-oxides (TEMPO or $\left.\mathrm{Me}_{3} \mathrm{NO}\right)^{23}$, refluxing in toluene or anisole or different synthesis conditions all gave inseparable mixtures of unidentified products containing free ${ }^{\text {iPr} P N N P}$ or insoluble precipitates (see ESI). In contrast, we found that exposure of a solution of 2 (containing 15\% 1) in benzene to a high-pressure $\mathrm{Hg}$-arc lamp (125 W) for 15 min leads to a color change from yellowgreen to dark green. ${ }^{31} \mathrm{P}\left\{{ }^{1} \mathrm{H}\right\} \mathrm{NMR}$ analysis of the mixture (Figure S36) showed selective conversion of $\mathbf{2}$ to $\mathbf{1}$ (Scheme 3). Surprisingly, irradiation of the reaction mixture for a total of 120 min leads to a dark amber-colored solution. ${ }^{1} \mathrm{H}$ and ${ }^{31} \mathrm{P}$ NMR analysis of the reaction mixture showed the loss of all diamagnetic signals due to formation of paramagnetic complex $\left[\mathrm{Fe}_{2}\left({ }^{\text {iPrPNNP* }}\right)(\mathrm{CO})_{5}\right](4)$, which was isolated as a dark-brown solid in $86 \%$ yield.

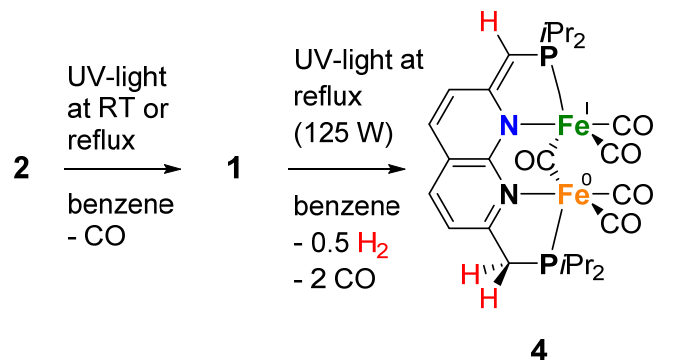

Scheme 3: The photochemical synthesis of complexes $\mathbf{1}$ and $\mathbf{4}$.

Despite numerous attempts, no single-crystals of $\mathbf{4}$ suitable for X-ray diffraction were obtained. However, based on spectroscopic analysis and follow-up reactivity (see below), we found that 4 comprises a diiron pentacarbonyl core contained within the dinucleating binding pocket of the

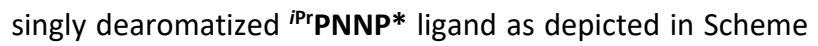
3. A balanced equation for the formation of $\mathbf{4}$ from $\mathbf{1}$ would require the loss of $2 \mathrm{CO}$ ligands and one $\mathrm{H}$ atom (i.e. 0.5 equiv of $\mathrm{H}_{2}$ ), which could originate from a process involving homolytic cleavage of a $\mathrm{C}-\mathrm{H}$ bond on the ligand side-arms. Indeed, headspace GC analysis of the reaction vessel after photolysis of $\mathbf{1}$ qualitatively confirmed the formation of both $\mathrm{CO}$ and $\mathrm{H}_{2}$ (see Figures $\mathrm{S} 85-87$ ).

The IR spectrum of $\mathbf{4}$ shows five bands in the CO region at $v_{\mathrm{CO}}$ of 1990,1929, 1893, 1871 and $1633 \mathrm{~cm}^{-1}$. The band at 1633 $\mathrm{cm}^{-1}$ is assigned to a bridging CO ligand, which is generally found at lower energy than a terminal CO ligand. ${ }^{24}$ This shows that the two iron centers are close enough in proximity to allow for a $\mathrm{CO}$ ligand to bind to both iron atoms. The X-band EPR spectrum of a toluene solution of $\mathbf{4}$ at room temperature displays an isotropic singlet $\left(g_{\text {iso }}=2.0475\right)$ without resolved hyperfine interactions (HFIs) (Figure 2A), indicative of a compound with a doublet electronic ground 


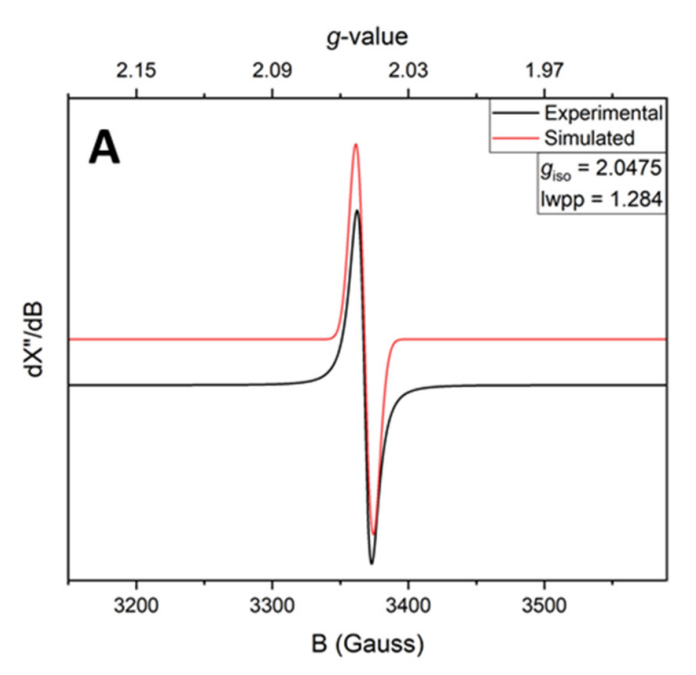

is a low spin $\mathrm{Fe}(\mathrm{I})$ complex. ${ }^{25}$ The calculated spin density plot of a DFT optimized (B3LYP/def2-TZVP) geometry of $4(S=1 / 2)$ shows $94 \%$ of the positive Mulliken spin density on the iron center (SOMO on $\mathrm{d}_{\mathrm{z}^{2}}$ orbital) (Figure $2 \mathrm{C}$ ). The DFT-calculated EPR parameters (B3LYP/def2-TZVP: $g_{\text {iso }}=2.0245, g_{11}=$ 2.0032, $g_{22}=2.0221, g_{33}=2.0483, A^{31 \mathrm{P} 1}=-19.0 \mathrm{MHz}, A^{31 \mathrm{P} 2}=$ $-12.4 \mathrm{MHz}$ ) are in good agreement with the simulated EPR spectrum of 4 at both room temperature and $30 \mathrm{~K}$, although the calculated HFIs with phosphorus are overestimated while the rhombicity is somewhat underestimated.

Cyclic voltammetry (CV) of $\mathbf{4}$ in THF solution using $\left[\mathrm{Bu}_{4} \mathrm{~N}\right] \mathrm{PF}_{6}$ as supporting electrolyte, displayed a reversible reduction at $E_{1 / 2}=-1.74 \mathrm{~V}$ vs. $\mathrm{Fc}^{+} / \mathrm{Fc}$ (Figure S65). Accordingly, the addition of one equiv of potassium naphthalenide $\left(\mathrm{K}\left(\mathrm{C}_{10} \mathrm{H}_{8}\right)\right)$ or potassium graphite $\left(\mathrm{KC}_{8}\right)$ to a brown THF solution of 4 at $-40{ }^{\circ} \mathrm{C}$ results in instantaneous formation of a dark yellow-brown solution. NMR analysis of the resulting mixture revealed a single major diamagnetic species, which was characterized as $\mathrm{K}(\mathrm{THF})_{x}\left[\mathrm{Fe}_{2}\left({ }^{i \mathrm{Pr} P N N P *}\right)(\mathrm{CO})_{5}\right](\mathbf{5})$ and was isolated as a brown solid material in $64 \%$ yield (Scheme 4 ). In contrast to $\mathbf{4}$, complex $\mathbf{5}$ is poorly soluble in benzene, and we found that using 0.95 equiv $\mathrm{K}\left(\mathrm{C}_{10} \mathrm{H}_{8}\right)$ enabled facile separation from the starting material without the formation of side products. It should be noted that the synthesis of 4 via the photochemical route depicted in Scheme 3 is poorly scalable above $10 \mathrm{mg}$, which is evident by the observation of an inseparable unknown diamagnetic byproduct upon oneelectron reduction (see ESI for more details). Therefore, a different more scalable method for the synthesis of $\mathbf{5}$ was developed (see below). The IR spectrum of $\mathbf{5}$ contains five $\mathrm{CO}$ bands at $v_{\mathrm{CO}}$ of 1993, 1930,1899, 1850 and $1635 \mathrm{~cm}^{-1}$, which are at similar energies as those observed in 4 (1990, 1929, 1893, 1871 and $1633 \mathrm{~cm}^{-1}$ ). This contradicts the larger degree of $\pi$-backdonation that would be expected upon oneelectron reduction of 4 . We reason that this is due the coordination of the potassium cation to carbonyl ligands, which is observed in the solid-state structure of $\mathbf{5}$ (Figure 3 and Figure S89) and has been reported to result in shorter $\mathrm{C}-\mathrm{O}$ bonds ${ }^{22 \mathrm{a}}$ and lower the $\mathrm{C}-\mathrm{O}$ stretching frequency. ${ }^{26}$ The ${ }^{31} \mathrm{P}\left\{{ }^{1} \mathrm{H}\right\}$ NMR spectrum of $\mathbf{5}$ in THF- $d_{8}$ at $298 \mathrm{~K}$ displays two doublets at $\delta=96.6 \mathrm{ppm}(J=5.2 \mathrm{~Hz})$ and $86.6 \mathrm{ppm}(J=5.2$

Figure 2: Experimental (black) and simulated (red) X-band EPR spectrum of 4 in toluene at room temperature $(A)$ or in a toluene glass at $30 \mathrm{~K}$ (B). A: Microwave freq. $9.650747 \mathrm{GHz}$, mod. amp. $4.000 \mathrm{G}$, power $0.6325 \mathrm{~mW}$. Simulation parameters: $g_{\text {iso }}=2.0475$, Gaussian line broadening $1.284 \mathrm{mT}$. B: Microwave freq. 9.641384 $\mathrm{GHz}$, mod. amp. $4.000 \mathrm{G}$, power $0.6325 \mathrm{~mW}$. Simulation parameters: $g$ [2.0081, 2.0282, 2.1028], Gaussian line broadening $1.153 \mathrm{mT}$. C: The DFT optimized structure of $\mathbf{4}$ and its spin density plot (isosurface value of $0.02 \mathrm{e} \cdot \mathrm{Bohr}^{-3}$ ).

state $(S=1 / 2)$. Performing low temperature EPR measurements at $30 \mathrm{~K}$ in a toluene glass revealed a rhombic signal with $g_{11}=2.0081, g_{22}=2.0282, g_{33}=2.1028$ without resolved HFIs present according to simulation (Figure 2B). These EPR results indicate that the paramagnetic center in $\mathbf{4}$ $\mathrm{Hz}$ ), indicating that the phosphorous nuclei are magnetically

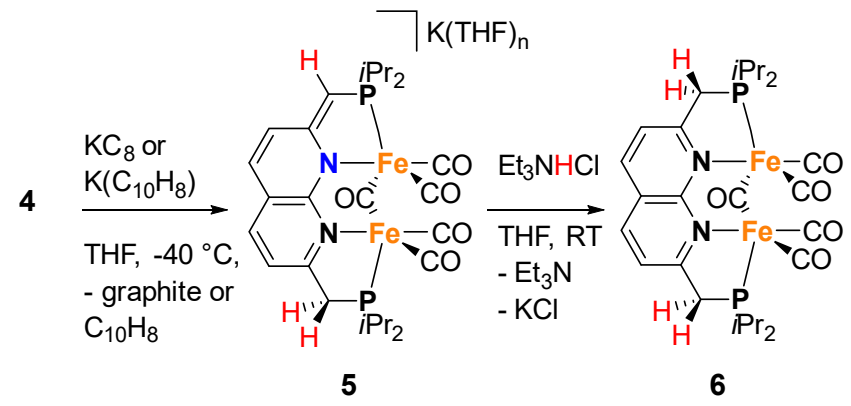

Scheme 4: The reduction of complex 4 to complex 5 and its protonation to 6 . 


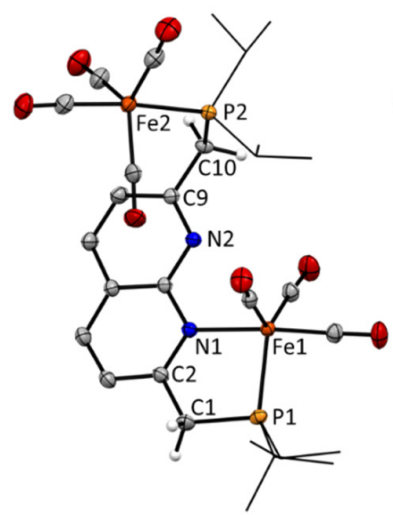

1

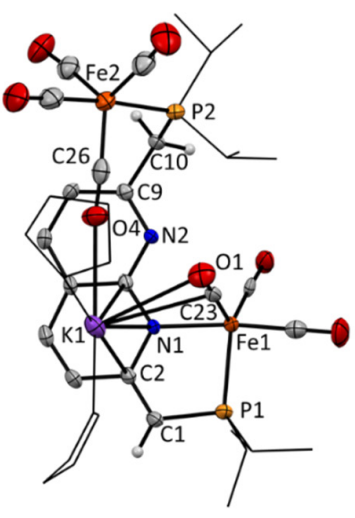

3

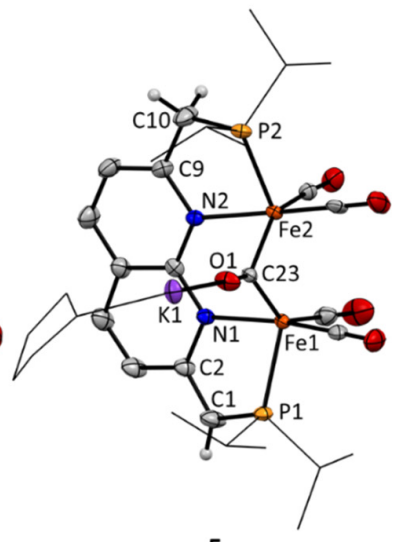

5

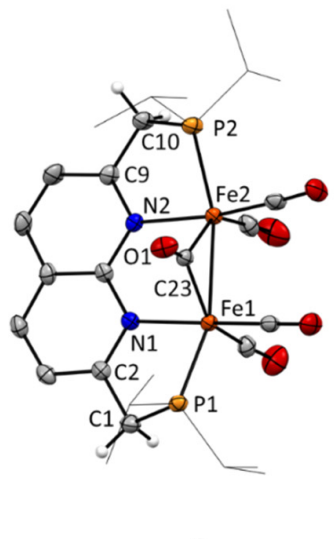

6

Figure 3: Displacement ellipsoid plots (50\% probability) of the asymmetric units of complex 1, 3, $\mathbf{5}$ and $\mathbf{6}$. Most hydrogen atoms and the benzene molecules in $\mathbf{6}$ are omitted and $i \operatorname{Pr}$ groups on P and the THF molecules in $\mathbf{3}$ and $\mathbf{5}$ are depicted as wireframe for clarity. For $\mathbf{5}$ and $\mathbf{6}$ only the major disorder component is shown.

coupled. As in 3, downfield shifted naphthyridine resonances and two methine/methylene doublets are observed at $\delta=$ $4.26 \mathrm{ppm}\left({ }^{2} J_{\mathrm{H}, \mathrm{P}}=2.8 \mathrm{~Hz}\right)$ and $3.18 \mathrm{ppm}\left({ }^{2} J_{\mathrm{H}, \mathrm{P}}=8.6 \mathrm{~Hz}\right)$, which are characteristic for a partially dearomatized iPrPNNP* ligand. The observation of a single methylene resonance that integrates for two protons is indicative of a on average $C_{s}$ symmetric species in solution. ${ }^{27}$ Although the solid-state structure of $\mathbf{5}$ displays a bridging carbonyl ligand orthogonal to the naphthyridine plane (Figure 3), we reason that the $\mu$ carbonyl undergoes rapid exchange on the NMR timescale giving on average a $C_{s}$-symmetric species in solution. This is supported by the absence of carbonyl resonances in the ${ }^{13} \mathrm{C}\left\{{ }^{1} \mathrm{H}\right\}$ NMR spectrum, which could be due to line broadening because of rapid exchange of the terminal and bridging carbonyl ligands. ${ }^{28}$ The solid-state structure features an anionic complex wherein a diironpentacarbonyl core is bound within the expanded pincer binding pocket, and a potassium cation (Figure 3 ). To the best of our knowledge, $\mathbf{5}$ is the first structure of a diiron carbonyl cluster bound to a multidentate phosphine-based ligand. Both iron centers display heavily distorted trigonal bipyramidal geometries, likely caused by the rigid chelating ligand environment. All carbonyl ligands are coordinated to potassium ions through their oxygen atoms, with the terminal carbonyl ligands coordinated to potassium ions from other unit cells (see figure S89). The Fe1-Fe2 distance $(2.5585(4) \AA)$ is typical for carbonyl bridged diiron complexes ${ }^{2 b, 29}$ and smaller than the sum of their covalent radii $^{30}$ (low spin iron(0): $2.64 \AA$ ). . However, quantum chemical analysis has shown that in such systems $\mathrm{Fe}-\mathrm{Fe}$ bonding is very weak and that a covalent bond is not present. ${ }^{31}$ NBO calculations of a DFT (BP86/def2-TZVP) gasphase optimized structure of $\mathbf{5}$ also indicate that there is no significant bonding interaction between the iron centers (Wiberg bond index 0.1781, Atom-Atom Net Linear NLMO/NPA Bond Orders 0.285).
Although $\mathbf{5}$ is stable at room temperature under inert atmosphere, it is highly susceptible to protonation. Filtrating small amounts of yellow-brown THF solutions of $\mathbf{5}$ over a Celite pad (note that Celite can serve as a mild proton source), causes a color change to reddish brown. ${ }^{31} \mathrm{P}$ NMR analysis of the resulting mixture showed quantitative conversion to a new complex. In line with this observation, reacting 5 with one equiv of $\mathrm{Et}_{3} \mathrm{NHCl}$ in THF affords complex $\left[\mathrm{Fe}_{2}\right.$ ( $\left.{ }^{\text {PrPNNP) }}(\mathrm{CO})_{5}\right](6)$ as a light brown solid in quantitative yields (see Scheme 4). The ${ }^{1} \mathrm{H},{ }^{13} \mathrm{C}$ and ${ }^{31} \mathrm{P}$ NMR spectra of 6 in THF- $d_{8}$ at $298 \mathrm{~K}$ show the expected number of resonances for a $C_{2 v}$-symmetric species. As for $\mathbf{5}$, this could indicate that rapid exchange of both terminal and bridging carbonyl ligands takes place or that the bridging carbonyl ligand is in the naphthyridine plane. The ${ }^{31} \mathrm{P}\left\{{ }^{1} \mathrm{H}\right\}$ NMR spectrum contains a single resonance at $\delta=100.9 \mathrm{ppm}$ and the resonances observed in the ${ }^{1} \mathrm{H}$ NMR spectrum are consistent with the presence of an aromatic naphthyridine backbone and two symmetric methylene linkers. Similar to 5 , the ${ }^{13} \mathrm{C}\left\{{ }^{1} \mathrm{H}\right\} \mathrm{NMR}$ spectrum of $\mathbf{6}$ does not contain resonances corresponding to the carbonyl ligands, which is attributed to rapid exchange between the carbonyl ligands. This would also explain the apparent observed $C_{2 v}$ symmetry of 6 in solution that is not observed in the solid-state (Figure 3 ). The solid-state structure of 6 reveals a neutral complex that displays the same diiron pentacarbonyl core as complex $\mathbf{5}$, but features a symmetric aromatic naphthyridine ligand backbone. Although the iPrPNNP ligand in $\mathbf{6}$ is less rigid than the iPrPNNP* ligand in 5, both iron centers still have heavily distorted trigonal bipyramidal geometries. The Fe1-Fe2 distance $(2.5538(7) \AA$ ) in 6 is almost identical to that observed in the solid-state structure of $\mathbf{5}$. Although 6 contains five carbonyl ligands, its IR spectrum only displays four CO bands located at $v_{\mathrm{CO}}=1992,1945,1886$, and 1695 $\mathrm{cm}^{-1}$. This feature is also observed in the Hessian vibrational spectrum of the DFT-optimized geometry of 6 (see Figures S93-96). 


\section{BDFE determination and intermediate trapping}

Although mononucleating lutidine-derived PNL $(L=P, N, S$ or other) pincer ligands are mainly known for their MLC involving dearomatization-aromatization through Brønsted acid-base chemistry, their CPET chemical non-innocence reactivity is not unprecedented. ${ }^{32}$ Pioneering work by Milstein and co-workers showed spontaneous $\mathrm{H}$-atom loss from the methylene linker in $\left[\left({ }^{\mathrm{R} P N P}\right) \mathrm{Co}(\mathrm{I})-X\right]\left(X=\mathrm{CH}_{3}\right.$ or $\left.\mathrm{H}\right)$ complexes in solution at room temperature, resulting in paramagnetic species $(S=1 / 2)$ featuring a proposed ligandcentered radical. $^{33}$ Chirik and co-workers further investigated this and showed that the resulting paramagnetic complex is best described as a low spin Co(II) complex bearing a monoanionic ligand with a dearomatized pyridine core. ${ }^{34}$ The facile $\mathrm{C}-\mathrm{H}$ cleavage was proposed to be inherent to the energetically accessible one-electron $\mathrm{Co}(\mathrm{I}) / \mathrm{Co}(\mathrm{II})$ redox couple paired with the ability for metal-toligand single-electron transfer.

To probe the feasibility of the proposed homolytic $\mathrm{C}\left(s p^{3}\right)-\mathrm{H}$ bond cleavage in the synthesis of $\mathbf{4}-$ and the potential of the PNNP platform to engage in cooperative bond activation through pathways involving chemical noninnocence - we were interested to study the bond dissociation free energy (BDFE) of the pseudobenzylic $\mathrm{C}\left(s p^{3}\right)-\mathrm{H}$ bonds in $\mathbf{1}$. In a thermochemical square scheme, the acidity of a reduced/oxidized species, the reduction potential of protonated/deprotonated species and the BDFE are thermodynamically related in free energies. ${ }^{35}$ Using the partial square scheme depicted in Scheme 5, the pseudobenzylic $\mathrm{C}\left(s p^{3}\right)-\mathrm{H}$ BDFE can be determined using the Bordwell equation (eq 1 ) with the $(\mathrm{C}-\mathrm{H}) \mathrm{p} K_{\mathrm{a}}$, the $E^{0}$, as estimated from a reversible electrochemical wave $E_{1 / 2}$, and the $\mathrm{H}^{+} / \mathrm{H}$ standard reduction potential in a certain solvent $\left(\mathrm{C}_{\mathrm{G}, \mathrm{sol}}\right)$.

$$
\operatorname{BDFE}_{\mathrm{sol}}(\mathrm{C}-\mathrm{H})=1.37 \mathrm{p} K_{\mathrm{a}}+23.06 E^{\circ}+\mathrm{C}_{\mathrm{G}, \mathrm{sol}}
$$

In non-aqueous media, the $\mathrm{p} K_{\mathrm{a}}$ of a compound can be determined by a bracketing approach. ${ }^{36}$ To this end, 3 was dissolved in THF together with equimolar amounts with a series of acids with known $\mathrm{p} K_{\mathrm{a}}$ values, and the equilibrium mixtures were analyzed by ${ }^{1} \mathrm{H},{ }^{19} \mathrm{~F}$ and ${ }^{31} \mathrm{P} \quad \mathrm{NMR}$ spectroscopy. ${ }^{37}$ Serendipitously, we found that the addition of one equiv of the $\mathrm{C}-\mathrm{H}$ acid 9-(perfluorophenyl)-9Hfluorene $\left(\mathrm{p} K_{\mathrm{a}}{ }^{\mathrm{DMSO}}=14.7\right)$ to 3 in THF- $d_{8}$ at $298 \mathrm{~K}$ led to a near $1: 1$ mixture of 1 and 3 . Given that some acid/base reactions can take days or weeks to equilibrate, even with strong bases, $^{38}$ we also investigated the reaction of $\mathbf{1}$ with the potassium salt of the 9-(perfluorophenyl)-9H-fluorenide anion. This reaction also provided a similar near $1: 1$ mixture of 1 and 3. This shows that thermodynamic equilibrium was established and that $\mathbf{1}$ and 9-(perfluorophenyl)-9Hfluorenene have a near equal $\mathrm{p} K_{\mathrm{a}}$ in THF. Since the $\mathrm{p} K_{\mathrm{a}}^{\text {THF }}$ of this 9-(perfluorophenyl)-9H-fluorene has not been reported, we used the relative acidity scale, $\mathrm{p} K_{\alpha}{ }^{\mathrm{THF}}{ }^{39}$ established by
Morris to estimate a $\mathrm{p} K_{\mathrm{a}}{ }^{\mathrm{THF}}$ of 28 for complex 1 (see ESI for more detail). ${ }^{38}$ Cyclic voltammetry of $\mathbf{3}$ in $\mathrm{THF} /\left[\mathrm{Bu}_{4} \mathrm{~N}\right] \mathrm{PF}_{6}$ displays a reversible redox couple at $E_{1 / 2}=-1.28 \mathrm{~V}\left(\mathrm{vs} \mathrm{Fc}^{+} / \mathrm{Fc}\right.$ ) when scanned in the positive direction (Figure S66). Together with the estimated $\mathrm{p} K_{\mathrm{a}}$, the $\mathrm{BDFE}_{\mathrm{C}-\mathrm{H}}$ in 1 was calculated as $70 \mathrm{kcal} \cdot \mathrm{mol}^{-1}$ using eq 1 with $C_{G, T H F}=61 \mathrm{kcal} \cdot \mathrm{mol}^{-}$ ${ }^{1.40}$ Using gas phase DFT calculations (B3LYP/def2-TZVP), BDFEs of $90 \mathrm{kcal} \cdot \mathrm{mol}^{-1}$ and $66 \mathrm{kcal} \cdot \mathrm{mol}^{-1}$ were calculated for the pseudobenzylic $\mathrm{C}\left(s p^{3}\right)-\mathrm{H}$ bonds in iPrPNNP and $\mathbf{1}$, respectively (see ESI for details). The calculated value for 1 is in good agreement with the experimentally determined value. The difference in $\mathrm{BDFE}_{\mathrm{C}-\mathrm{H}}$ between the free ligand and complex is comparable to what Chirik and coworkers computationally determined for ${ }^{\text {tBupNP }}\left(80 \mathrm{kcal} \mathrm{mol}^{-1}\right)$ and ${ }^{t \text { Bu }}$ PNPCo(I)-X complexes (43-50 kcal mol $\left.{ }^{-1}\right) .{ }^{34}$
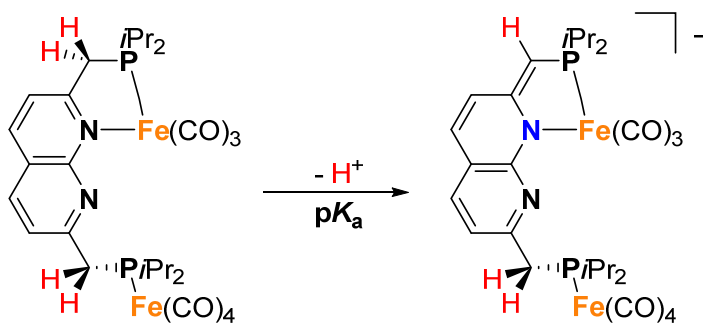

1
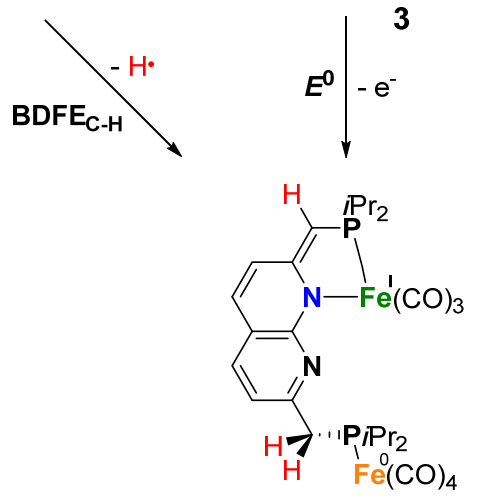

7

Scheme 5: Partial thermochemical square scheme of complex 1 to determine the $\mathrm{BDFE}_{\mathrm{C}-\mathrm{H}}$.

To experimentally verify the low $\mathrm{BDFE}_{\mathrm{C}-\mathrm{H}}$ in complex $\mathbf{1}$, its reactivity towards hydrogen atom transfer (HAT) using 2,4,6tri-tert-butylphenoxyl radical (TBP) (BDFEO-H $=80.6 \mathrm{kcal} \cdot \mathrm{mol}^{-}$ ${ }^{1}$ in DMSO) $)^{35}$ as the HAT reagent was studied. Directly upon addition of one equiv of TBP to a solution of 1 in THF at ambient temperature a color change from dark green to brown was observed. ${ }^{1} \mathrm{H}$ and ${ }^{31} \mathrm{P}\left\{{ }^{1} \mathrm{H}\right\}$ NMR analysis of the reaction mixture showed full conversion of 1 to an NMR silent compound (iPrPNNP*) $\mathrm{Fe}_{2}(\mathrm{CO})_{7}(7$, Scheme 5$)$ and the formation of 2,4,6-tri-tert-butylphenol (TBP-H), which was confirmed by NMR and IR spectroscopy. Although complex 7 is readily prepared by an $\mathrm{H}$-atom abstraction from $\mathbf{1}$, we were surprised to discover it is unstable in solution and in the solid state, even when stored inside a $\mathrm{N}_{2}$-filled glovebox. EPR and IR spectroscopy and headspace GC analysis show 
that this is due to facile loss of $\mathrm{CO}$ ligands upon exposure to visible light concomitant with the formation of complex 4 (See ESI for details). Nonetheless, this process does not proceed quantitatively even when applying a dynamic vacuum or in refluxing THF. Fortunately, overnight exposure of a THF solution of $\mathbf{7}$ to a weak (TLC) UV source results in quantitative conversion to 4 (see ESI and Scheme 7). Moreover, this transformation was found to be insensitive to the scale of the reaction - unlike the harsh photochemical route starting from 1 (Scheme 3) - thereby providing a reproducible route for the synthesis of mixed-valent 4 .

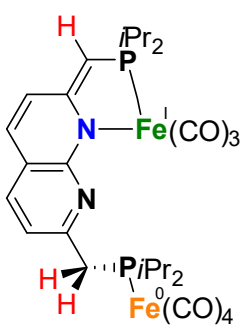

7

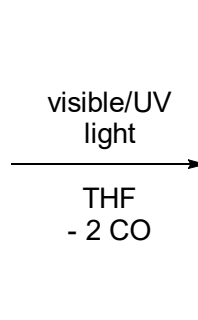

(1)

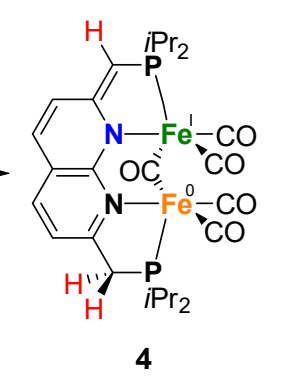

4
Scheme 7: Light induced conversion of 7 to 4.

Despite the sensitive nature of $\mathbf{7}$, with strict exclusion of light and appropriate precautions spectroscopically clean samples of $\mathbf{7}$ can be obtained. The ATR-IR spectrum of a freshly prepared reaction mixture containing 7 and TBP-H in THF displays CO bands $v_{\text {co }}$ at 2043, 1965 and 1923 (with a shoulder at approx. 1930) $\mathrm{cm}^{-1}$ together with a weak band at $1883 \mathrm{~cm}^{-1}$. The $\mathrm{CO}$ band at $v_{\mathrm{CO}}=2043 \mathrm{~cm}^{-1}$ is solely observed in complexes 1-3 and is characteristic for the P-bound $\mathrm{Fe}(\mathrm{CO})_{4}$ outside the naphthyridine pocket, showing that this fragment is present in 7. The addition of TBP to a toluene solution of $\mathbf{1}$ at room temperature followed by rapid freezing in liquid nitrogen after 5 minutes enabled obtaining a clean EPR spectrum of 7 at both room temperature and $30 \mathrm{~K}$ (Figure 4). Note that freezing the samples after 10 minutes already resulted in observable formation of complex 4 . The isotropic EPR spectrum of in situ prepared 7 at room temperature (Figure $4 \mathrm{~A})$ reveals a doublet $\left(g_{\text {iso }}=2.0418\right)$ due to $\mathrm{HFI}$ with phosphorus $\left(A_{\text {iso }}^{31 \mathrm{P}}=58.3 \mathrm{MHz}\right)$. The EPR spectrum of 7 collected in a toluene glass at $30 \mathrm{~K}$ displayed a rhombic signal with $g_{11}=2.0027, g_{22}=2.0478, g_{33}=2.0684$, and HFIs with a single P-nucleus of $A_{11}{ }^{31 \mathrm{P}}=40.2 \mathrm{MHz}, A_{22}{ }^{31 \mathrm{P}}$ $=71.2 \mathrm{MHz}$ and $A_{33}{ }^{31 \mathrm{P}}=62.9 \mathrm{MHz}$. In contrast to 4 , HFIs with phosphorus are clearly present and resolved for 7. A minor contribution of $0.1 \%$ weight is attributed to unreacted TBP $\left(g_{\text {iso }}=2.005\right)$. Similarly to complex 4 , these EPR results indicate that the paramagnetic center in complex $\mathbf{7}$ is a low spin Fe(I) complex. The DFT calculated (B3LYP/def2-TZVP) $g$ values and HFIs of $\mathbf{7}$ correlate well with the simulated EPR spectrum at $30 \mathrm{~K}$, with exception of the $A_{11}{ }^{31 \mathrm{P}} \mathrm{HFI}$ that is overestimated by $20 \mathrm{MHz}$. Interestingly, the gas-phase optimized geometry of $\mathbf{7}$ with an $S=1 / 2$ ground state adopts a distorted square pyramidal geometry around the iron tricarbonyl fragment (Figure S91), which has been observed before for other low-spin $\mathrm{Fe}(\mathrm{I})$ complexes. ${ }^{41}$ The positive Mulliken spin density is primarily centered on iron (89\%) with the SOMO in the $\mathrm{d}_{\mathrm{z}^{2}}$ orbital oriented towards phosphorus and the empty sixth coordination site (Figure 4C). The spin density on $\mathbf{7}$ is orthogonally oriented compared to 4, which might explain the large differences in phosphorus HFIs between the two compounds.
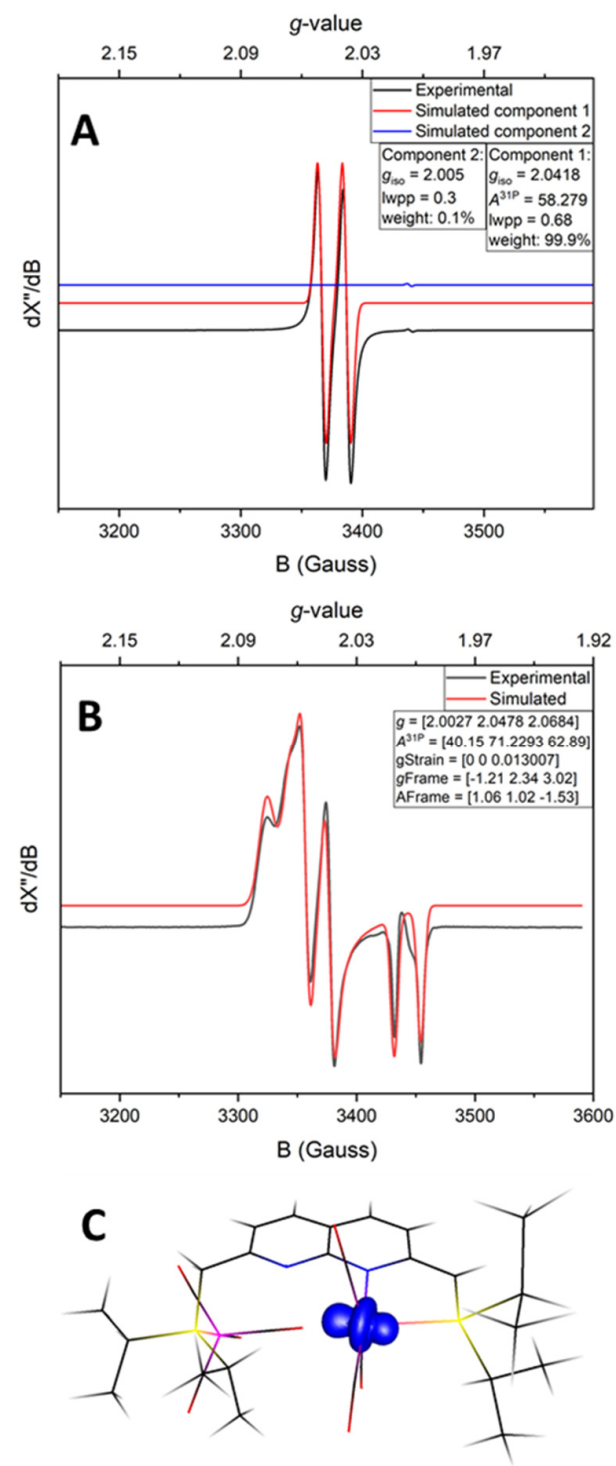

Figure 4: Experimental (black) and simulated (red) X-band EPR spectrum of $\mathbf{7}$ in toluene at room temperature (A) or in a toluene glass at $30 \mathrm{~K}$ (B). (A) Microwave freq. $9.649849 \mathrm{GHz}$, mod. amp. $4.000 \mathrm{G}$, power $0.6325 \mathrm{~mW}$. Simulation parameters component 1 (7): $g_{\text {iso }}=2.0418, A^{31 P}=58.279 \mathrm{MHz}$, Gaussian line broadening 0.68 $\mathrm{mT}$, weight $=99.9 \%$. Simulation parameters component 2 (TBP): $g_{\text {iso }}$ $=2.005$, Gaussian line broadening $0.3 \mathrm{mT}$, weight $=0.1 \%$. (B) Microwave freq. $9.650852 \mathrm{GHz}$, mod. amp. $2.000 \mathrm{G}$, power 0.2000 $\mathrm{mW}$. Simulation parameters: $g[2.0027,2.0478,2.0684], A^{31 P}$ [40.15, 71.2293, 62.89], $g$-strain [0 0 0.013007], $g$-frame [-1.21, 2.34, 3.02], A-frame [1.06 $1.02-1.53]$. (C) The structure of 7 and its

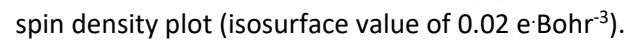


Despite numerous attempts, we were unsuccessful in growing crystals of $\mathbf{7}$ that were suitable for X-ray diffraction. Nonetheless, the spectroscopic data, which are supported by computations, are in line with 7 being a low-spin paramagnetic Fe(I) complex, as depicted in Scheme 5. This is further supported by the observation that the addition of 1.9 equiv of $\mathrm{KC}_{8}$ to a freshly prepared solution of complex 7 (from a reaction of 1 with TBP) (excess $\mathrm{KC}_{8}$ for formed TBP-H), yields complex 3 as the main product based on NMR spectroscopy (see ESI for detail). This shows that hydrogen atom abstraction from $\mathbf{1}$ is not associated with simultaneous CO ligand loss.

In contrast to the reactivity of 1 , one equiv of TBP at ambient temperature in THF does not abstract a $\mathrm{H}$-atom from 2 or iPrPNNP, suggesting that the coordination mode influences the pseudobenzylic $\mathrm{C}\left(s p^{3}\right)-\mathrm{H}$ bond strength. This lack of reactivity agrees with the computationally determined BDFEs (B3LYP/def2-TZVP) of $91 \mathrm{kcal} \cdot \mathrm{mol}^{-1}$ and 90 $\mathrm{kcal} \cdot \mathrm{mol}^{-1}$ for the pseudobenzylic $\mathrm{C}-\mathrm{H}$ bonds in $\mathbf{2}$ and iPrPNNP, respectively. Compared to the low (calculated) BDFE $_{\mathrm{C}-\mathrm{H}}$ of $66 \mathrm{kcal} \cdot \mathrm{mol}^{-1}$ for 1 , this suggests that the coordination of the iron carbonyl fragment in the ligand $\mathrm{PN}$ binding pocket leads to significant decrease of the $\mathrm{C}\left(s p^{3}\right)-\mathrm{H}$ bond strength. We reason that this can be attributed to a

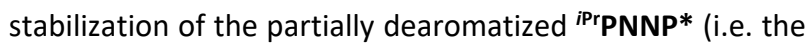
conjugate base) and $\mathrm{Fe}(\mathrm{I})$ center in this coordination mode, thereby enabling facile metal-to-ligand single-electron transfer associated with $\mathrm{H}$-atom abstraction.

\section{Electrochemistry}

Considering our observations that the PNNP platforms enables MMC, CPET and heterolytic MLC like processes three features that are key to [FeFe]-hydrogenase's activity - we decided to investigate complex 4 for the electrochemical hydrogen evolution reaction (HER). Accordingly, CV experiments of complex 4 with phenol as proton source $\left(\mathrm{p} K_{\mathrm{a}}{ }^{\mathrm{DMSO}}=18.0\right)^{42}$ were performed in $\mathrm{THF} /\left[\mathrm{Bu}_{4} \mathrm{~N}\right] \mathrm{PF}_{6}$. Although no visible reaction is observed upon the addition of one equiv phenol to a solution of 4 , the one-electron reduction event at $-1.74 \mathrm{~V}$ vs $\mathrm{Fc}^{+} / \mathrm{Fc}$ associated with the formation of $\mathbf{5}$ loses its reversibility (Figure S68). This suggests that upon reduction of $\mathbf{4}$ to $\mathbf{5}$ the latter is protonated by phenol to give $\mathbf{6}$, which is in line with the facile protonation observed during the synthesis of $\mathbf{5}$. This is further supported by the observation of a second partially reversible reductive event with an onset potential at $-1.95 \mathrm{~V}$ vs. $\mathrm{Fc}^{+} / \mathrm{Fc}$. This potential is identical to the $\mathrm{E}_{1 / 2}$ potential of the first reductive event observed in the cyclic voltammogram of $\mathbf{6}$, and this event also loses its reversibility in the presence of one equiv phenol (Figure S72 and S73). Unfortunately, no indications in the voltammograms of electrocatalytic reduction are observed in the presence of additional equivalents of phenol (Figure S69). In contrast, CV experiments of 4 ( $1 \mathrm{mM})$ with triethyl ammonium hexafluorophosphate (TEA) as proton source $\left(\mathrm{p} K_{\mathrm{a}}\right.$ DMSO $=$ 9.0 $)^{43}$ in $\mathrm{THF} /\left[\mathrm{Bu}_{4} \mathrm{~N}\right] \mathrm{PF}_{6}$ gave different results. Already upon addition of one equiv TEA ( $1 \mathrm{mM}$ ) to 4 , a color change from amber to orange-green was observed. We propose that this stronger acid protonates the ${ }^{\text {iPr}}$ PNNP* ligand of $\mathbf{4}$ prior to reduction. Nonetheless, the cyclic voltammogram (Figure S70) shows an irreversible reductive event with an onset potential at $-1.95 \mathrm{~V}$ vs. $\mathrm{Fc}^{+} / \mathrm{Fc}$, identical to the potential observed in the same experiments of $\mathbf{4}$ or $\mathbf{6}$ with phenol. In contrast to the experiments with phenol, an additional small reductive event with an onset potential at $-2.30 \mathrm{~V} \mathrm{vs}$. $\mathrm{Fc}^{+} / \mathrm{Fc}$ feature is observed in the CVs of either 4 or $\mathbf{6}$ with 1 equiv TEA (Figure S70 and 5). Interestingly, for both 4 (Figure S71) and $\mathbf{6}$ (Figure 5), higher [TEA] shifts of the onset potential of this event towards less negative potentials and results in increased cathodic current. Both observations are clear signs of electrocatalytic proton reduction. ${ }^{44}$ This shows that these diiron complexes are catalysts for electrochemical proton reduction, like [FeFe] hydrogenase, albeit with inferior catalytic performance. Although it is likely that the ligand methylene $\mathrm{C}-\mathrm{H}$ bonds will be even weaker in more reduced diiron complexes that are accessed at these negative potentials, it is unclear whether the chemical non-innocence of the PNNP ligand described above plays a role in the electrocatalytic pathway. Future research will focus on obtaining mechanistic insights into the operating reaction mechanism and optimizing the catalytic activity of these diiron systems in the HER.

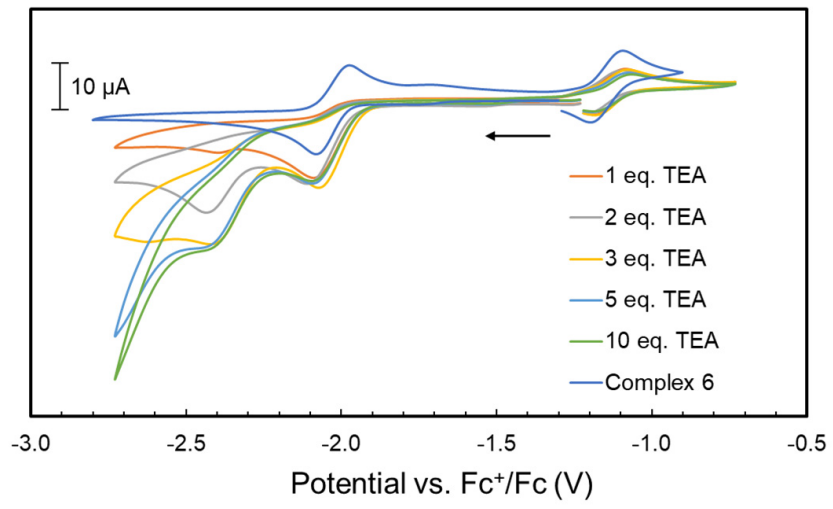

Figure 5: Cyclic voltammograms of complex 6 with the addition of 1-10 mM of TEA in THF $/\left[\mathrm{Bu}_{4} \mathrm{~N}\right] \mathrm{PF}_{6}\left(\right.$ scan rate $\left.=0.1 \mathrm{~V} \cdot \mathrm{s}^{-1}\right)$; the arrow indicates the scan direction.

\section{Summary \& Conclusion}

This work describes the preparation of the iPrPNNP 'expanded pincer' ligand and its rich coordination chemistry with iron carbonyls. Similar to our previous reports on related dicopper systems, the ligand's methylene linkers can be deprotonated concomitant with partial dearomatization of the naphthyridine core. Interestingly, we show that the methylene linkers in the PNNP ligand are also susceptible to CPET reactivity concomitant with the formation of 
dihydrogen. The CPET chemistry was evaluated both experimentally and computationally, leading to the conclusion that coordination of the iron carbonyl center within the ligand PN binding pocket weakens the pseudobenzylic $\mathrm{C}\left(s p^{3}\right)-\mathrm{H}$ bond dissociation free energy (BDFE) by $\sim 25 \mathrm{kcal} \mathrm{mol}^{-1}$ with respect to a P-bound analogue or the free ligand. H-atom abstraction using 2,4,6-tri-tertbutylphenoxyl radical enabled trapping of an unstable potential intermediate, which undergoes facile loss of two carbonyl ligands. EPR analysis and computational methods demonstrate that hydrogen atom abstraction proceeds via a net CPET process and yields low-spin Fe(I) complexes with a closed-shell anionic iPrPNNP* ligand. This reactivity was leveraged to develop a reliable synthetic route toward complexes wherein both iron centers are bound in close proximity within the expanded pincer ligand. Finally, we demonstrated that the diiron carbonyl complexes are catalysts for the electrochemical hydrogen evolution reaction.

In conclusion, the PNNP expanded pincer ligand platform allows the synthesis of bimetallic first row transition metals and is capable of metal-ligand cooperativity (MLC) through both proton-responsiveness and chemical non-innocence. Both pathways involve partial dearomatization of the naphthyridine core, but the latter is enabled by metal-to-ligand single-electron transfer. To the best of our knowledge, this work demonstrates the first example of ligand chemical non-innocence in naphthyridinebased bimetallic complexes. The low bond-dissociation free energy of the pseudobenzylic $\mathrm{C}\left(s p^{3}\right)-\mathrm{H}$ bonds in the PNNP ligand should be carefully considered when these dinucleating PNNP ligands are combined with metals that undergo facile single-electron redox changes. Future research in our group will focus on obtaining mechanistic understanding of the reported electrochemical HER catalysis and on exploiting the described two-sided MLC strategies for bimetallic bond activation processes of relevance to small molecule activation and homogeneous catalysis.

\section{Supporting information}

Experimental procedures and details, NMR spectra, and computational and crystallographic computational details can be found in the supporting information. CCDC 21108882110891 contain the supplementary crystallographic data for this paper. These data are provided free of charge by The Cambridge Crystallographic Data Centre.

NMR and computational data files can be obtained free of charge from the 4TU data repository: DOI: $10.4121 / 16685086$

\section{Acknowledgements}

This work was supported by The Netherlands Organization for Scientific Research (START-UP grant 740.018.019 to
D.L.J.B.). Access to supercomputer facilities was sponsored by NWO Exacte en Natuurwetenschappen (Physical Sciences). Sander de Vos and Marc-Etienne Moret are acknowledged for valuable discussions and suggestions. 


\section{References}

${ }^{1}$ a) M. Can, F. A. Armstrong, S. W. Ragsdale, Chem. Rev. 2014, 114, 4149-4174; b) W.Lubitz, H. Ogata, O. Rüdiger,E.Reijerse, Chem. Rev. 2014, 114, 4081-4148; c) M.D.Wodrich, X. Hu, Nat. Rev.Chem. 2017, 2, 0099; d) D. Sippel, M. Rohde, J. Netzer,C.Trncik, J. Gies, K. Grunau, I. Djurdjev-ic, L. Decamps ,S.L.A. Andrade, O. Einsle, Science 2018, 359,1484-1489.

2 a) W. Lubitz, H. Ogata, O. Rüdiger, E. Reijerse, Chem. Rev. 2014, 114, 4081-4148; b) Y. Li, T. B. Rauchfuss, Chem. Rev. 2016, 116, 7043-7077; c) J. A. Birrell, V. Pelmenschikov, N. Mishra, H. Wang, Y. Yoda, K. Tamasaku, T. B. Rauchfuss, S. P. Cramer, W. Lubitz, S. DeBeer, J. Am. Chem. Soc. 2020, 142, 222-232.

${ }^{3}$ a) H. Land, M. Senger, G. Berggren, S. T. Stripp, ACS Catal. 2020, 10, 7069-7086; b) J. T. Kleinhaus, F. Wittkamp, S. Yadav, D. Siegmund, U.-P. Apfel, Chem. Soc. Rev. 2021, 50, 1668-1784.

${ }^{4}$ H. Tai, S. Hirota, S. T. Stripp, Acc. Chem. Res. 2021, 54, 232-241.

${ }^{5}$ a) J. Duan, M. Senger, J. Esselborn, V. Engelbrecht, F. Wittkamp, U.-P. Apfel, E. Hofmann, S. T. Stripp, T. Happe, M. Winkler, Nat. Commun. 2018, 9, 4726.

${ }^{6}$ O. Lampret, J. Duan, E. Hofmann, M. Winkler, F. A. Armstrong, T. Happe, Proc. Natl. Acad. Sci. 2020, 117, $20520-20529$.

${ }^{7}$ For recent reviews see: a) M.Iglesias, E. Sola, L. A. Oro in Homo- and Heterobimetallic Complexes in Catalysis: Cooperative Catalysis (Ed.:P. Kalck),Springer International Publishing, Cham, 2016; pp. 31 -58; b) N. P. Mankad, Chem. Eur. J. 2016, 22, 58225829; c) D. R. Pye, N. P. Mankad, Chem. Sci. 2017, 8, 1705-1718; d) C. M. Farley, C. Uyeda, Trends Chem. 2019, 1, 497-509; e) N. Xiong, G. Zhang, X. Sun, R. Zeng, Chinese J. Chem. 2020, 38, 185-201; f) S. Rey, H. Tsurugi, K. Mashima Coord. Chem. Rev. 2018, 355, 223-239; g) R. Maity, B. S. Birenheide, F. Breher, B. Sarkar ChemCatChem 2021, 13, 2337-2370; h) Q. Wang, S. H. Brooks, T. Liu, N. C. Tomson, Chem. Commun. 2021, 57, 2839-2853.

${ }^{8}$ Selected recent examples a) A. Z. Spentzos, M. R. Gau, P. J. Carroll, N. C. Tomson Chem Commun, 2020, 56, 9675-9678; S. Zhang, P. Cui, T. Liu, Q. Wang, T. J. Longo, L. M. Thierer, B. C. Manor, M. R. Gau, P. J. Carroll, G. C. Papaefthymiou, N. C. Tomson Angew. Chem. Int. Ed. 2020, 59, 15215; c) M. C. Eaton, V. J. Catalano, J. Shearer, L. J. Murray J. Am. Chem. Soc. 2021, 143, 56495653; d) A. Nicolay, M. S. Ziegler, D. W. Small, R. Grünbauer, M. Scheer and T. D. Tilley, Chem. Sci. 2020, 11, 1607-1616; e) O. Rivada-Wheelaghan, A. Comas-Vives, R. R. Fayzullin, A. Lledós, J. R. Khusnutdinova Chem. Eur. J. 2020, 26, 12168-12179; f) ${ }^{9}$ Selected additional examples a) M. Li, S. K. Gupta, S. Dechert, S. Demeshko, F. Meyer Angew.Chem. Int.Ed. 2021, 60,14480 14487 b) A. Brinkmeier, R. A. Schulz, M. Buchhorn, C.-J. Spyra, S. Dechert, S. Demeshko, V. Krewald, F. Meyer, J. Am. Chem. Soc. 2021, 143, 10361-10366; c) T. Ouyang, H.-J. Wang, H.-H. Huang, J.-W. Wang, S. Guo, W.-J. Liu, D.-C. Zhong, T.-B. Lu, Angew. Chemie Int. Ed. 2018, 57, 16480-16485 d) A. R. Scheerder, M. Lutz, D. L. J. Broere ChemComm 2020, 56, 8198-8201; e) R. C. Cammarota, M. V. Vollmer, J. Xie, J. Ye, J. C. Linehan, S. A. Burgess, A. M. Appel, L. Gagliardi, C. C. Lu, J. Am. Chem. Soc. 2017, 139, 14244-14250; f) W. Tao, J. K. Bower, C. E. Moore, S. Zhang, J. Am. Chem. Soc. 2019, 141, 10159-10164.

10 a) A. N. Desnoyer, A. Nicolay, P. Rios, M. S. Ziegler, T. D. Tilley Acc. Chem. Res. 2020, 53, 1944-1956; b) C. He, A. M. Barrios, D. Lee, J. Kuzelka, R. M. Daavydov, S. J. Lippard, J. Am. Chem. Soc. 2000, 122, 12683-12690; c) C. He, J. L. Dubois, B. Hedman, K. O. Hodgson, S. J. Lippard, Angew. Chem. Int. Ed. 2001, 40, 1484-1487; d) J. K. Bera, N. Sadhukhanb, M. Majumdar, Eur. J. Inorg. Chem. 2009, 4023-4038; M. Sarkar, H. Doucet, J. K. Bera, Chem. Commun. 2013, 49, 9764- 9766.

${ }^{11}$ a) Van Koten, G.; Kirchner, K.; Moret, M-. E. Metal-Ligand Co-operativity, Topics in organometallic chemistry, Vol. 68 (Eds.: G. van Koten, K. Kirchner, M.-E. Moret), Springer, Berlin, 2021; b) M. R. Elsby, R. T. Baker, Chem. Soc. Rev. 2020, 49, 89338987.c) T. Higashi, S. Kusumoto, K. Nozaki, Chem. Rev. 2019, 119, 10393-10402; d) L. Alig, M. Fritz, S. Schneider, Chem. Rev. 2019, 119, 2681-2751; e) J. R. Khusnutdinova, D. Milstein, Angew. Chemie Int. Ed. 2015, 54, 12236-12273; Angew. Chemie 2015, 127, 12406-12445.

12 a) D. L. DuBois, Inorg. Chem. 2014, 53, 3935-3960; b) D. Milstein, Philos. Trans. R. Soc. A Math. Phys. Eng. Sci. 2015, 373, 20140189; c) J. I. van der Vlugt, J. N. H. Reek, Angew. Chemie Int. Ed. 2009, 48, 8832-8846; d) C. Gunanathan, D. Milstein, Acc. Chem. Res. 2011, 44, 588-602.

${ }^{13}$ a) V. Lyaskovskyy, B. De Bruin, ACS Catal. 2012, 2, 270-279; b) R. Arevalo, P. J. Chirik, J. Am. Chem. Soc. 2019, 141, 9106-9123; c) O. R. Luca, R. H. Crabtree, Chem. Soc. Rev. 2013, 42, 1440-1459; d) J. I. van der Vlugt, Chem. - A Eur. J. 2019, 25, 2651-2662; e) N. P. van Leest, F. J. de Zwart, M. Zhou, B. de Bruin, JACS Au 2021, 1, 1101-1115.

14 a) Y.-Y. Zhou, D. R. Hartline, T. J. Steiman, P. E. Fanwick, C. Uyeda, Inorg. Chem. 2014, 53, 11770-11777; b) Y.-Y. Zhou, C. Uyeda, Science 2019, 363, 857-862; c) J. M. Andjaba, C. J. Rybak, Z. Wang, J. Ling, J. Mei, C. Uyeda, J. Am. Chem. Soc. 2021, 143, 3975-3982; d) A. K. Maity, A. E. Kalb, M. Zeller, C. Uyeda, Angew. Chemie Int. Ed. 2021, 60, 1897-1902; Angew. Chem. 2021, $133,1925-1930$.

${ }^{15}$ a) E. Kounalis, M. Lutz, D. L. J. Broere, Organometallics 2020, 39, 585-592; b) E. Kounalis, M. Lutz, D. L. J. Broere, Chem. $-A$ 
Eur. J. 2019, 25, 13280-13284.

${ }^{16}$ a) F. Schneck, M. Finger, M. Tromp, S. Schneider, Chem. - A Eur. J. 2017, 23, 33-37; b) K. E. Rosenkoetter, M. K. Wojnar, B. J. Charette, J. W. Ziller, A. F. Heyduk, Inorg. Chem 2018, 57, 41; c) M.-C. Chang, K. A. Jesse, A. S. Filatov, J. S. Anderson, Chem. Sci. 2019, 10, 1360-1367 ; d) A. J. McNeece, K. A. Jesse, A. S. Filatov, J. E. Schneider, J. S. Anderson, Chem. Commun. 2021, 57, 3869-3872.

17 a) B. Meunier, S. P. de Visser, S. Shaik, Chem. Rev. 2004, 104, 3947-3980; b) J. W. Whittaker, Chem. Rev. 2003, 103, 23472364.

${ }^{18}$ H. Inoue, T. Nakagome, T. Kuroiwa, T. Shirai, E. Fluck, Zeitschrift für Naturforsch. B 1987, 42, 573-578.

${ }^{19}$ a) R. Bramley, B. N. Figgis, R. S. Nyholm, Trans. Faraday Soc. 1962, 58, 1893-1896; b) F. A. Cotton, A. Danti, J. S. Waugh, R. W. Fessenden, J. Chem. Phys. 1958, 29, 1427-1428; c) J. P. Jesson, P. Meakin, J. Am. Chem. Soc. 1973, 95, 1344-1346; d) P. Portius, M. Bühl, M. W. George, F.-W. Grevels, J. J. Turner, Organometallics 2019, 38, 4288-4297; e) P. Portius, M. Bühl, M. W. George, F.-W. Grevels, J. J. Turner, Organometallics 2019, 38, 4288-4297.

20 a) H. T. Dieck, G. Hahn, Z. Anorg. Allg. Chem. 1989, 577, 74-82; b) Y.-M. Wuu, J. G. Bentsen, C. G. Brinkley, M. S. Wrighton, Inorg. Chem. 1987, 26, 530-540.

${ }^{21}$ D. J. Darensbourg, H. H. Nelson, C. L. Hyde, Inorg. Chem. 1974, 13, 2135-2145.

${ }^{22}$ For iron: a) A. K. Hickey, C. H. Chen, M. Pink, J. M. Smith, Organometallics 2015, 34, 4560-4566; b) A. K. Hickey, W.-T. Lee, C.H. Chen, M. Pink, J. M. Smith, Organometallics 2016, 35, 3069-3073; c) A. V. Polezhaev, C. J. Liss, J. Telser, C.-H. Chen, K. G. Caulton, Chem. - A Eur. J. 2018, 24, 1330-1341. For Cobalt: A. V. Polezhaev, C. J. Liss, J. Telser, C.-H. Chen, K. G. Caulton, Chem. A Eur. J. 2018, 24, 1330-1341. For manganese: T. K. Mukhopadhyay, N. L. Maclean, M. Flores, T. L. Groy, R. J. Trovitch, Inorg. Chem 2018, 57, 6065-6075..

${ }^{23}$ a) T.-Y. Luh, Coord. Chem. Rev. 1984, 60, 255-276; b) J. A.S. Howell, G. Walton, M.-C. Tirvengadum, A. D. Squibb, M. G. Palin, J. Organomet. Chem. 1991, 401, 91-123; c) Y. Shvo, E. Hazum, J. Chem. Soc. Chem. Commun. 1975, 829-830; d) A. J. Birch, L. F. Kelly, J. Organomet. Chem. 1985, 286, c5-c7.

24 a) I. S. Butler, S. Kishner, K. R. Plowman, J. Mol. Struct. 1978, 43, 9-15; b) I. A. Oxton, J. Mol. Struct. 1982, 78, 77-84; c) D. T. Moore, J. Oomens, J. R. Eyler, G. Meijer, G. von Helden, D. P. Ridge, J. Am. Chem. Soc. 2004, 126, 14726-14727.

${ }^{25}$ For example: a) Y. Ohki, R. Hoshino, K. Tatsumi, Organometallics 2016, 35, 1368-1375; b) ) R. E. Cowley, M. R. Golder, N. A. Eckert, M. H. Al-Afyouni, P. L. Holland, Organometallics 2013, 32, 5289-5298; c) C. J. Adams, R. B. Bedford, E. Carter, N. J. Gower, M. F. Haddow, J. N. Harvey, M. Huwe, M. Á. Cartes, S. M. Mansell, C. Mendoza, et al., J. Am. Chem. Soc. 2012, 134, 10333-10336; d) M. Glatz, B. Stöger, B. Bichler, G. Bauer, L. F. Veiros, M. Pignitter, K. Kirchner, Eur. J. Inorg. Chem. 2020, 2020, 1101-1105.

${ }^{26}$ J. P. Shupp, A. R. Rose, M. J. Rose, Dalt. Trans. 2017, 46, 9163-9171.

${ }^{27}$ In several unpublished compounds wherein both faces of the naphthyridine plane are inequivalent we always see two independent resonances with a large ${ }^{2} \mathrm{~J}_{\mathrm{H}, \mathrm{H}}$ coupling constant due to the diastereotopic nature of these protons.

${ }^{28}$ a) L. Kruczynski, J. Takats, Inorg. Chem. 1976, 15, 3140-3147; b) J. A.S. Howell, G. Walton, M.-C. Tirvengadum, A. D. Squibb, M. G. Palin, J. Organomet. Chem. 1991, 401, 91-123; c) D. C. Harris, E. Rosenberg, J. D. Roberts, J. Chem. Soc., Dalt. Trans. 1974, 2398-2403; d) G. W. Grynkewich, T. J. Marks, Inorg. Chem. 1976, 15, 1307-1314.

${ }^{29}$ R. H. Duncan Lyngdoh, H. F. Schaefer, R. B. King, Chem. Rev. 2018, 118, 11626-11706.

${ }^{30}$ B. Cordero, V. Gómez, A. E. Platero-Prats, M. Revés, J. Echeverría, E. Cremades, F. Barragán, S. Alvarez, Dalt. Trans. $2008,2832$.

31 H. Chevreau, C. Martinsky, A. Sevin, C. Minot, B. Silvi, New J. Chem. 2003, 27, 1049-1053.

32 a) Gloaguen, C. Rebreyend, M. Lutz, P. Kumar, M. Huber, J. I. van der Vlugt, S. Schneider, B. de Bruin, Angew. Chemie Int. Ed. 2014, 53, 6814-6818; Angew. Chem. 2014, 126, 6932-6936; b) C. Rebreyend, V. Mouarrawis, M. A. Siegler, J. I. van der Vlugt, B. de Bruin, Eur. J. Inorg. Chem. 2019, 2019, 4249-4255.

33 E. Khaskin, Y. Diskin-Posner, L. Weiner, G. Leitus, D. Milstein, Chem. Commun 2013, 49, 2771.

${ }^{34}$ S. P. Semproni, C. Milsmann, P. J. Chirik, J. Am. Chem. Soc. 2014, 136, 9211-9224.

35 J. J. Warren, T. A. Tronic, J. M. Mayer, Chem. Rev. 2010, 110, 6961-7001.

${ }^{36}$ a) A. E. Carpenter, C. Chan, A. L. Rheingold, J. S. Figueroa, Organometallics 2016, 35, 2319-2326; b) S. Tretiakov, L. Witteman, M. Lutz, M. Moret, Angew. Chemie Int. Ed. 2021, 60, 9618-9626.

37 F. G. Bordwell, Acc. Chem. Res. 1988, 21, 456-463.

${ }^{38}$ K. Abdur-Rashid, T. P. Fong, B. Greaves, D. G. Gusev, J. G. Hinman, S. E. Landau, A. J. Lough, R. H. Morris, J. Am. Chem. Soc. 2000, 122, 9155-9171.

${ }^{39}$ The known $\mathrm{p} K_{\mathrm{a}}{ }^{\mathrm{DMSO}}$ value was converted to $\mathrm{p} K_{\alpha}{ }^{\mathrm{THF}}$ using Morris' empirical relationship: $\mathrm{p} K_{\mathrm{a}}{ }^{\mathrm{DMSO}}(\mathrm{HA})=0.85 \mathrm{p} K_{\alpha}{ }^{\mathrm{THF}}(\mathrm{HA})-9.6$

${ }^{40} \mathrm{~F}$. Schneck, M. Finger, M. Tromp, S. Schneider, Chem. - A Eur. J. 2017, 23, 33-37.

${ }^{41}$ a) M. Glatz, B. Stöger, B. Bichler, G. Bauer, L. F. Veiros, M. Pignitter, K. Kirchner, Eur. J. Inorg. Chem. 2020, 2020, 1101-1105. b) M. J. Therien, W. C. Trogler, J. Am. Chem. Soc. 1986, 108, 3697-3702; c) J. H. MacNeil, A. C. Chiverton, S. Fortier, M. C. Baird, R. C. Hynes, A. J. Williams, K. F. Preston, T. Ziegler, J. Am. Chem. Soc. 1991, 113, 9834-9842; d) A. M. Tondreau, C. 
Milsmann, E. Lobkovsky, P. J. Chirik, Inorg. Chem. 2011, 50, 9888-9895.

42 F. G. Bordwell, R. J. McCallum, W. N. Olmstead, J. Org. Chem. 1984, 49, 1424-1427.

${ }^{43}$ a) I. M. Kolthoff, M. K. Chantooni, S. Bhowmik, J. Am. Chem. Soc. 1968, 90, 23-28; b) M. R. Crampton, I. A. Robotham, J. Chem. Res. 1997, 22-23.

${ }^{44}$ C. P. Andrieux, C. Blocman, J. M. Dumas-Bouchiat, F. M'Halla, J. M. Savéant, J. Electroanal. Chem. Interfacial Electrochem. $1980,113,19-40$. 